\title{
Some common fixed point theorems on partial metric spaces satisfying implicit relation
}

\author{
G. S. SALUJA
}

\begin{abstract}
The aim of this article is to prove some fixed point and common fixed point theorems on partial metric spaces satisfying implicit relation. Our results extend and generalize several results from the existing literature.
\end{abstract}

\section{Introduction AND Preliminaries}

The well known Banach contraction principle is the most celebrated result in fixed point theory and its applications. Banach contraction principle guarantees that any contraction map on complete metric space has a unique fixed point. In 1969, Kannan [15] was the first, who gave a new contractive condition for which a map need not be continuous even if it has fixed point in complete metric space. In 1972, Chatterjae [13] also generalized the Banach contraction condition and obtained a fixed point result. The well-known Banach contraction theorem [8] is stated as follows.

Theorem 1. Let $(X, d)$ be a complete metric space and let $T: X \rightarrow X$ be a mapping satisfying the contractive condition

$$
d(T(x), T(y)) \leq \alpha d(x, y)
$$

for all $x, y \in X$, where $\alpha \in[0,1)$ is a constant. Then $T$ has a unique fixed point in $X$ and that point can be obtained as a limit of repeated iteration of the mapping at any point of $X$.

A new space called a partial metric space (PMS) has been introduced by Matthews $([24,25])$. After introducing partial metric space, Matthews [25] also proved the partial metric version of the Banach fixed point theorem which is an analogous of Banach contraction principle, this makes the partial metric space relevant in fixed point theory. In 1999, Heckmann [14]

2010 Mathematics Subject Classification. Primary: 47H10, 54H25.

Key words and phrases. Fixed point, common fixed point, implicit relation, partial metric space.

Full paper. Received 4 November 2019, accepted 27 January 2020, available online 29 February 2020. 
established some results using a generalization of the partial metric function called a weak partial metric function. In 2004, Oltra and Valero [29] also generalized the Matthews's fixed point theorem in a complete partial metric space in the sense of O'Neill. Then many authors gave some generalizations of the results of Matthews and proved some fixed point theorems on this space (see, e.g., [1, 2, 3, 4, 5, 16, 17, 18, 20, 29, 39], see, also $[11,12,28,34,35,37])$. Also, the concept of PMS provide to study denotational semantics of dataflow networks [24, 25, 38, 40].

In 2016, Kir and Kiziltunc introduced the concept of $T_{F}$ contractive mappings in partial metric space and established a generalization of Banach's, Kannan's and Chatterjae's fixed point theorems for the concept of partial metric space.

The study of common fixed point theorems using implicit relations was introduced by V. Popa [31] in 1999. Later on various authors used implicit relations and proved fixed point and common fixed point theorems in different spaces (see, e.g., [7, 9, 10, 23, 27, 30, 32, 33, 36] and many others).

The definition of a partial metric space is given by Matthews (see [24]) as follows.

Definition 1 ([24]). Let $X$ be a nonempty set and let $p: X \times X \rightarrow \mathbb{R}^{+}$be a function satisfy:

(pm1) $x=y \Leftrightarrow p(x, x)=p(x, y)=p(y, y)$,

(pm2) $p(x, x) \leq p(x, y)$,

(pm3) $p(x, y)=p(y, x)$,

(pm4) $p(x, y) \leq p(x, z)+p(z, y)-p(z, z)$,

for all $x, y, z \in X$. Then $p$ is called partial metric on $X$ and the pair $(X, p)$ is called partial metric space.

It is clear that if $p(x, y)=0$, then from (pm1) and (pm2) we obtain $x=y$. But if $x=y, p(x, y)$ may not be zero. Various applications of this space has been extensively investigated by many authors (see [22], [39] for details).

Example 1 ([6]). Let $X=\mathbb{R}^{+}$and $p: X \times X \rightarrow \mathbb{R}^{+}$given by $p(x, y)=$ $\max \{x, y\}$ for all $x, y \in \mathbb{R}^{+}$. Then $\left(\mathbb{R}^{+}, p\right)$ is a partial metric space.

Example 2 ([6]). Let $X=\{[a, b]: a, b \in \mathbb{R}, a \leq b\}$. Then $p([a, b],[c, d])=$ $\max \{b, d\}-\min \{a, c\}$ defines a partial metric $p$ on $X$.

Remark 1 ([19]). Let $(X, p)$ be a partial metric space.

(1) The function $d_{p}: X \times X \rightarrow \mathbb{R}^{+}$defined as $d_{p}(x, y)=2 p(x, y)-$ $p(x, x)-p(y, y)$ is a (usual) metric on $X$ and $\left(X, d_{p}\right)$ is a (usual) metric space.

(2) The function $d_{q}: X \times X \rightarrow \mathbb{R}^{+}$defined as $d_{q}(x, y)=\max \{p(x, y)-$ $p(x, x), p(x, y)-p(y, y)\}$ is a (usual) metric on $X$ and $\left(X, d_{q}\right)$ is a (usual) metric space. 
Note that each partial metric $p$ on $X$ generates a $T_{0}$ topology $\tau_{p}$ on $X$, whose base is a family of open $p$-balls $\left\{B_{p}(x, \varepsilon): x \in X, \varepsilon>0\right\}$ where $B_{p}(x, \varepsilon)=\{y \in X: p(x, y) \leq p(x, x)+\varepsilon\}$ for all $x \in X$ and $\varepsilon>0$.

On a partial metric space the notions of convergence, the Cauchy sequence, completeness and continuity are defined as follows [24].

Definition 2 ([24]). Let $(X, p)$ be a partial metric space. Then:

$\left(a_{1}\right)$ a sequence $\left\{x_{n}\right\}$ in $(X, p)$ is said to be convergent to a point $x \in X$ if and only if $p(x, x)=\lim _{n \rightarrow \infty} p\left(x_{n}, x\right)$,

$\left(a_{2}\right)$ a sequence $\left\{x_{n}\right\}$ is called a Cauchy sequence if $\lim _{m, n \rightarrow \infty} p\left(x_{m}, x_{n}\right)$ exists and finite,

$\left(a_{3}\right)(X, p)$ is said to be complete if every Cauchy sequence $\left\{x_{n}\right\}$ in $X$ converges to a point $x \in X$ with respect to $\tau_{p}$.

Furthermore,

$$
\lim _{m, n \rightarrow \infty} p\left(x_{m}, x_{n}\right)=\lim _{n \rightarrow \infty} p\left(x_{n}, x\right)=p(x, x) .
$$

$\left(a_{4}\right)$ A mapping $F: X \rightarrow X$ is said to be continuous at $x_{0} \in X$ if for every $\varepsilon>0$, there exists $\delta>0$ such that $F\left(B_{p}\left(x_{0}, \delta\right)\right) \subset B_{p}\left(F\left(x_{0}\right), \varepsilon\right)$.

Definition 3 ([26]). Let $(X, p)$ be a partial metric space. Then:

$\left(b_{1}\right)$ a sequence $\left\{x_{n}\right\}$ in $(X, p)$ is called 0 -Cauchy if $\lim _{m, n \rightarrow \infty} p\left(x_{m}, x_{n}\right)=$ 0 ,

$\left(b_{2}\right)(X, p)$ is said to be 0 -complete if every 0-Cauchy sequence $\left\{x_{n}\right\}$ in $X$ converges to a point $x \in X$, such that $p(x, x)=0$.

Lemma 1 ([24, 25]). Let $(X, p)$ be a partial metric space. Then:

$\left(c_{1}\right)$ a sequence $\left\{x_{n}\right\}$ in $(X, p)$ is a Cauchy sequence if and only if it is a Cauchy sequence in the metric space $\left(X, d_{p}\right)$,

$\left(c_{2}\right)(X, p)$ is complete if and only if the metric space $\left(X, d_{p}\right)$ is complete,

$\left(c_{3}\right)$ a subset $E$ of a partial metric space $(X, p)$ is closed if a sequence $\left\{x_{n}\right\}$ in $E$ such that $\left\{x_{n}\right\}$ converges to some $x \in X$, then $x \in E$.

Lemma 2 ([2]). Assume that $x_{n} \rightarrow z$ as $n \rightarrow \infty$ in a partial metric space $(X, p)$ such that $p(z, z)=0$. Then $\lim _{n \rightarrow \infty} p\left(x_{n}, y\right)=p(z, y)$ for every $y \in X$.

Now, we introduce an implicit relation to investigate some fixed point and common fixed point theorems in partial metric spaces.

Definition 4 (Implicit Relation). Let $\Psi$ be the family of all real valued continuous functions $\psi: \mathbb{R}_{+}^{3} \rightarrow \mathbb{R}_{+}$non-decreasing in the first argument for three variables. For some $\mu \in[0,1)$, we consider the following conditions.

(Ir 1$)$ For $x, y \in \mathbb{R}_{+}$, if $y \leq \psi\left(x, \frac{x+y}{2}, \frac{x+y}{2}\right)$, then $y \leq \mu x$,

$(\operatorname{Ir} 2)$ For $x \in \mathbb{R}_{+}$, if $y \leq \psi(y, 0, y)$, then $y=0$ since $\mu \in[0,1)$,

(Ir 3$)$ For $x \in \mathbb{R}_{+}$, if $y \leq \psi\left(0, \frac{y}{2}, \frac{y}{2}\right)$, then $y=0$. 
The purpose of this paper is to establish some fixed point and common fixed point theorems in the setting of partial metric spaces satisfying implicit relation. Our results extend and generalize several results from the existing literature.

\section{Main Results}

In this section we shall prove some fixed point and common fixed point theorems using implicit relation in the framework of partial metric spaces.

Theorem 2. Let $(X, p)$ be a complete partial metric space and let $T: X \rightarrow$ $X$ be a mapping satisfying the inequality

$$
\begin{array}{r}
p(T x, T y) \leq \psi\left\{p(x, y), \frac{1}{2}[p(x, T x)+p(y, T y)],\right. \\
\left.\frac{1}{2}[p(x, T y)+p(y, T x)]\right\},
\end{array}
$$

for all $x, y \in X$ and some $\psi \in \Psi$. If $\psi$ satisfies the conditions (Ir 1$)$, (Ir2) and (Ir3), then $T$ has a unique fixed point in $X$.

Proof. For each $x_{0} \in X$ and $n \in \mathbb{N}$, put $x_{n+1}=T x_{n}$. It follows from (2) and (pm4) that

$$
\begin{aligned}
& p\left(x_{n}, x_{n+1}\right)=p\left(T x_{n-1}, T x_{n}\right) \\
& \leq \psi\left\{p\left(x_{n-1}, x_{n}\right), \frac{1}{2}\left[p\left(x_{n-1}, T x_{n-1}\right)+p\left(x_{n}, T x_{n}\right)\right],\right. \\
& \left.\frac{1}{2}\left[p\left(x_{n-1}, T x_{n}\right)+p\left(x_{n}, T x_{n-1}\right)\right]\right\} \\
& \leq \psi\left\{p\left(x_{n-1}, x_{n}\right), \frac{1}{2}\left[p\left(x_{n-1}, x_{n}\right)+p\left(x_{n}, x_{n+1}\right)\right],\right. \\
& \left.\frac{1}{2}\left[p\left(x_{n-1}, x_{n+1}\right)+p\left(x_{n}, x_{n}\right)\right]\right\} \\
& \leq \psi\left\{p\left(x_{n-1}, x_{n}\right), \frac{1}{2}\left[p\left(x_{n-1}, x_{n}\right)+p\left(x_{n}, x_{n+1}\right)\right],\right. \\
& \left.\frac{1}{2}\left[p\left(x_{n-1}, x_{n}\right)+p\left(x_{n}, x_{n+1}\right)-p\left(x_{n}, x_{n}\right)\right]\right\} \\
& \leq \psi\left\{p\left(x_{n-1}, x_{n}\right), \frac{1}{2}\left[p\left(x_{n-1}, x_{n}\right)+p\left(x_{n}, x_{n+1}\right)\right],\right. \\
& \left.\frac{1}{2}\left[p\left(x_{n-1}, x_{n}\right)+p\left(x_{n}, x_{n+1}\right)\right]\right\}
\end{aligned}
$$

Since $\psi$ satisfies the condition ( $\operatorname{Ir} 1)$, there exists $\mu \in[0,1)$ such that

$$
p\left(x_{n}, x_{n+1}\right) \leq \mu p\left(x_{n-1}, x_{n}\right) \leq \mu^{n} p\left(x_{0}, x_{1}\right) .
$$

Set $F_{n}=p\left(x_{n}, x_{n+1}\right)$ and $F_{n-1}=p\left(x_{n-1}, x_{n}\right)$, then from (4), we obtain

$$
F_{n} \leq \mu F_{n-1} \leq \mu^{2} F_{n-2} \leq \cdots \leq \mu^{n} F_{0} .
$$


Now we show that $\left\{x_{n}\right\}$ is a Cauchy sequence in $X$. Let $m, n>0$ with $m>n$, then by using (pm4) and equation (4), we have

$$
\begin{aligned}
p\left(x_{n}, x_{m}\right) \leq & p\left(x_{n}, x_{n+1}\right)+p\left(x_{n+1}, x_{n+2}\right)+\cdots+p\left(x_{n+m-1}, x_{m}\right) \\
& -p\left(x_{n+1}, x_{n+1}\right)-p\left(x_{n+2}, x_{n+2}\right)-\cdots-p\left(x_{n+m-1}, x_{n+m-1}\right) \\
\leq & \mu^{n} p\left(x_{0}, x_{1}\right)+\mu^{n+1} p\left(x_{0}, x_{1}\right)+\cdots+\mu^{n+m-1} p\left(x_{0}, x_{1}\right) \\
= & \mu^{n}\left[p\left(x_{0}, x_{1}\right)+\mu p\left(x_{0}, x_{1}\right)+\cdots+\mu^{m-1} p\left(x_{0}, x_{1}\right)\right] \\
= & \mu^{n}\left[1+\mu+\cdots+\mu^{m-1}\right] F_{0} \\
\leq & \mu^{n}\left(\frac{1-\mu^{m-1}}{1-\mu}\right) F_{0} .
\end{aligned}
$$

Taking $n, m \rightarrow \infty$ in the above inequality, we get $p\left(x_{n}, x_{m}\right) \rightarrow 0$ since $0<\mu<1$, hence $\left\{x_{n}\right\}$ is a Cauchy sequence in $X$. Thus by Lemma 1 this sequence will also Cauchy in $\left(X, d_{p}\right)$. In addition, since $(X, p)$ is complete, $\left(X, d_{p}\right)$ is also complete. Thus there exists $u \in X$ such that $x_{n} \rightarrow u$ as $n \rightarrow \infty$. Moreover by Lemma 1 ,

$$
p(u, u)=\lim _{n \rightarrow \infty} p\left(u, x_{n}\right)=\lim _{n, m \rightarrow \infty} p\left(x_{n}, x_{m}\right)=0,
$$

implies

$$
\lim _{n \rightarrow \infty} d_{p}\left(u, x_{n}\right)=0
$$

Now, we show that $u$ is a fixed point of $T$. Notice that due to (5), we have $p(u, u)=0$. By using inequality (2), we get

$$
\begin{aligned}
p\left(x_{n+1}, T u\right) & =p\left(T x_{n}, T u\right) \\
& \leq \psi\left\{p\left(x_{n}, u\right), \frac{1}{2}\left[p\left(x_{n}, T x_{n}\right)+p(u, T u)\right],\right. \\
& =\psi\left\{p\left(x_{n}, z\right), \frac{1}{2}\left[p\left(x_{n}, T u\right)+p\left(u, T x_{n}\right)\right]\right\} \\
\left.\frac{1}{2}\left[p\left(x_{n}, T u\right)+p\left(u, x_{n+1}\right)\right]\right\} . &
\end{aligned}
$$

Note that $\psi \in \Psi$, then taking the limit as $n \rightarrow \infty$ and using (5) and Lemma 2 , we get

$$
p(u, T u) \leq \psi\left\{0, \frac{1}{2} p(u, T u), \frac{1}{2} p(u, T u)\right\} .
$$

Since $\psi$ satisfies the condition $(\operatorname{Ir} 3)$, then $p(u, T u)=0$. This shows that $u=T u$. Thus $u$ is a fixed point of $T$.

Now to show that the fixed point of $T$ is unique. Let $u_{1}, u_{2}$ be fixed points of $T$ with $u_{1} \neq u_{2}$. We shall prove that $u_{1}=u_{2}$. It follows from equation (2) and (5) that

$$
p\left(u_{1}, u_{2}\right)=p\left(T u_{1}, T u_{2}\right)
$$




$$
\begin{aligned}
& \leq \psi\left\{p\left(u_{1}, u_{2}\right), \frac{1}{2}\left[p\left(u_{1}, T u_{1}\right)+p\left(u_{2}, T u_{2}\right)\right]\right. \\
& \left.\frac{1}{2}\left[p\left(u_{1}, T u_{2}\right)+p\left(u_{2}, T u_{1}\right)\right]\right\} \\
& =\psi\left\{p\left(u_{1}, u_{2}\right), \frac{1}{2}\left[p\left(u_{1}, u_{1}\right)+p\left(u_{2}, u_{2}\right)\right]\right. \\
& \left.\frac{1}{2}\left[p\left(u_{1}, u_{2}\right)+p\left(u_{2}, u_{1}\right)\right]\right\} \\
& =\psi\left\{p\left(u_{1}, u_{2}\right), 0, p\left(u_{1}, u_{2}\right)\right\}
\end{aligned}
$$

Since $\psi$ satisfies the condition $(\operatorname{Ir} 2)$, then we get

$$
\begin{aligned}
p\left(u_{1}, u_{2}\right) & \leq \mu p\left(u_{1}, u_{2}\right) \\
& \Rightarrow p\left(u_{1}, u_{2}\right)=0, \text { since } 0<\mu<1 .
\end{aligned}
$$

This shows that $u_{1}=u_{2}$. Thus the fixed point of $T$ is unique. This completes the proof.

Theorem 3. Let $F$ and $G$ be two mappings on a complete partial metric space $(X, p)$ and

$$
\begin{aligned}
& p(F x, G y) \leq \psi\left\{p(x, y), \frac{1}{2}[p(x, F x)+p(y, G y)]\right. \\
&\left.\frac{1}{2}[p(x, G y)+p(y, F x)]\right\}
\end{aligned}
$$

for all $x, y \in X$ and some $\psi \in \Psi$. Then $F$ and $G$ have a unique common fixed point in $X$.

Proof. For each $x_{0} \in X$. Put $x_{2 n+1}=F x_{2 n}$ and $x_{2 n+2}=G x_{2 n+1}$ for $n=0,1,2, \ldots$ It follows from $(7),(\mathrm{pm} 4)$ and Lemma 1 that

$$
\begin{aligned}
p\left(x_{2 n+1}, x_{2 n}\right) & =p\left(F x_{2 n}, G x_{2 n-1}\right) \\
& \leq \psi\left\{p\left(x_{2 n}, x_{2 n-1}\right), \frac{1}{2}\left[p\left(x_{2 n}, F x_{2 n}\right)+p\left(x_{2 n-1}, G x_{2 n-1}\right)\right]\right. \\
& =\psi\left\{p\left(x_{2 n}, x_{2 n-1}\right), \frac{1}{2}\left[p\left(x_{2 n}, G x_{2 n-1}\right)+p\left(x_{2 n-1}, F x_{2 n}\right)\right]\right\} \\
& \left.\frac{1}{2}\left[p\left(x_{2 n}, x_{2 n}\right)+p\left(x_{2 n-1}, x_{2 n+1}\right)\right]\right\} \\
& \leq \psi\left\{p\left(x_{2 n}, x_{2 n-1}\right), \frac{1}{2}\left[p\left(x_{2 n}, x_{2 n+1}\right)+p\left(x_{2 n-1}, x_{2 n}\right)\right],\right. \\
& \leq \psi\left\{p\left(x_{2 n}, x_{2 n-1}\right), \frac{1}{2}\left[p\left(x_{2 n}, x_{2 n+1}\right)+p\left(x_{2 n-1}, x_{2 n}\right)\right],\right.
\end{aligned}
$$




$$
\left.\frac{1}{2}\left[p\left(x_{2 n-1}, x_{2 n}\right)+p\left(x_{2 n}, x_{2 n+1}\right)\right]\right\} .
$$

Since $\psi$ satisfies the condition ( $\operatorname{Ir} 1)$, there exists $\mu \in[0,1)$ such that

$$
p\left(x_{2 n+1}, x_{2 n}\right) \leq \mu p\left(x_{2 n}, x_{2 n-1}\right) \leq \mu^{2 n} p\left(x_{1}, x_{0}\right) .
$$

Now we show that $\left\{x_{n}\right\}$ is a Cauchy sequence in $X$. Let $m, n>0$ with $m>n$, then by using (pm4) and equation (9), we have

$$
\begin{aligned}
p\left(x_{n}, x_{m}\right) \leq & p\left(x_{n}, x_{n+1}\right)+p\left(x_{n+1}, x_{n+2}\right)+\cdots+p\left(x_{n+m-1}, x_{m}\right) \\
& -p\left(x_{n+1}, x_{n+1}\right)-p\left(x_{n+2}, x_{n+2}\right)-\cdots-p\left(x_{n+m-1}, x_{n+m-1}\right) \\
\leq & \mu^{n} p\left(x_{0}, x_{1}\right)+\mu^{n+1} p\left(x_{0}, x_{1}\right)+\cdots+\mu^{n+m-1} p\left(x_{0}, x_{1}\right) \\
= & \mu^{n}\left[p\left(x_{0}, x_{1}\right)+\mu\left(x_{0}, x_{1}\right)+\cdots+\mu^{m-1} p\left(x_{0}, x_{1}\right)\right] \\
= & \mu^{n}\left[1+\mu+\cdots+\mu^{m-1}\right] p\left(x_{0}, x_{1}\right) \\
\leq & \mu^{n}\left(\frac{1-\mu^{m-1}}{1-\mu}\right) p\left(x_{0}, x_{1}\right) .
\end{aligned}
$$

Taking $n, m \rightarrow \infty$ in the above inequality, we get $p\left(x_{n}, x_{m}\right) \rightarrow 0$ since $0<\mu<1$, hence $\left\{x_{n}\right\}$ is a Cauchy sequence in $X$. Thus by Lemma 1 this sequence will also Cauchy in $\left(X, d_{p}\right)$. In addition, since $(X, p)$ is complete, $\left(X, d_{p}\right)$ is also complete. Thus there exists $v \in X$ such that $x_{n} \rightarrow v$ as $n \rightarrow \infty$. Moreover by Lemma 1 ,

$$
p(v, v)=\lim _{n \rightarrow \infty} p\left(v, x_{n}\right)=\lim _{n, m \rightarrow \infty} p\left(x_{n}, x_{m}\right)=0,
$$

implies

$$
\lim _{n \rightarrow \infty} d_{p}\left(v, x_{n}\right)=0 .
$$

Now we have to prove that $v$ is a common fixed point of $F$ and $G$. For this, consider

$$
\begin{aligned}
& p\left(x_{2 n+1}, F v\right)=p\left(F x_{2 n}, F v\right) \\
& \leq \psi\left\{p\left(x_{2 n}, v\right), \frac{1}{2}\left[p\left(x_{2 n}, F x_{2 n}\right)+p(v, F v)\right],\right. \\
&\left.\frac{1}{2}\left[p\left(x_{2 n}, F v\right)+p\left(v, F x_{2 n}\right)\right]\right\} \\
&=\psi\left\{p\left(x_{2 n}, v\right), \frac{1}{2}\left[p\left(x_{2 n}, x_{2 n+1}\right)+p(v, F v)\right],\right. \\
&\left.\frac{1}{2}\left[p\left(x_{2 n}, F v\right)+p\left(v, x_{2 n+1}\right)\right]\right\} .
\end{aligned}
$$

Note that $\psi \in \Psi$, then using (10), Lemma 2 and taking the limit as $n \rightarrow \infty$, we get

$$
p(v, F v) \leq \psi\left(0,0, \frac{p(v, F v)}{2}, \frac{p(v, F v)}{2}\right) .
$$


Since $\psi$ satisfies the condition $(\operatorname{Ir} 3)$, then $p(v, F v)=0$. This shows that $v=F v$ for all $v \in X$. Similarly, we can show that $v=G v$. Thus $v$ is a common fixed point of $F$ and $G$.

Now to show that the common fixed point of $F$ and $G$ is unique. For this, let $v^{\prime}$ be another common fixed point of $F$ and $G$, that is, $F v^{\prime}=G v^{\prime}=v^{\prime}$ with $v^{\prime} \neq v$. Then we have to show that $v=v^{\prime}$. It follows from equation (7) and (10) that

$$
\begin{aligned}
p\left(v, v^{\prime}\right) & =p\left(F v, G v^{\prime}\right) \\
& \leq \psi\left\{p\left(v, v^{\prime}\right), \frac{1}{2}\left[p(v, F v)+p\left(v^{\prime}, G v^{\prime}\right)\right],\right. \\
& \left.\frac{1}{2}\left[p\left(v, G v^{\prime}\right)+p\left(v^{\prime}, F v\right)\right]\right\} \\
& =\psi\left\{p\left(v, v^{\prime}\right), \frac{1}{2}\left[p(v, v)+p\left(v^{\prime}, v^{\prime}\right)\right],\right. \\
\left.\frac{1}{2}\left[p\left(v, v^{\prime}\right)+p\left(v^{\prime}, v\right)\right]\right\} & \psi\left\{p\left(v, v^{\prime}\right), 0, p\left(v, v^{\prime}\right)\right\} .
\end{aligned}
$$

Since $\psi$ satisfies the condition $(\operatorname{Ir} 2)$, then we get

$$
\begin{aligned}
p\left(v, v^{\prime}\right) & \leq \mu p\left(v, v^{\prime}\right) \\
& \Rightarrow p\left(v, v^{\prime}\right)=0, \text { since } 0<\mu<1 .
\end{aligned}
$$

Thus, we get $v=v^{\prime}$. This shows that $v$ is the unique common fixed point of $F$ and $G$. This completes the proof.

Theorem 4. Let $F_{1}$ and $F_{2}$ be two continuous mappings on a complete partial metric space $(X, p)$ and

$$
\begin{aligned}
& p\left(F_{1}^{m} x, F_{2}^{n} y\right) \leq \psi\left\{p(x, y), \frac{1}{2}\left[p\left(x, F_{1}^{m} x\right)+p\left(y, F_{2}^{n} y\right)\right],\right. \\
&\left.\frac{1}{2}\left[p\left(x, F_{2}^{n} y\right)+p\left(y, F_{1}^{m} x\right)\right]\right\}
\end{aligned}
$$

for all $x, y \in X$, where $m$ and $n$ are some integers and some $\psi \in \Psi$. Then $F_{1}$ and $F_{2}$ have a unique common fixed point in $X$.

Proof. Since $F_{1}^{m}$ and $F_{2}^{n}$ satisfy the conditions of Theorem 3. So $F_{1}^{m}$ and $F_{2}^{n}$ have a unique common fixed point. Let $z$ be the common fixed point. Then, we have

$$
\begin{aligned}
F_{1}^{m} z=z & \Rightarrow F_{1}\left(F_{1}^{m} z\right)=F_{1} z \\
& \Rightarrow F_{1}^{m}\left(F_{1} z\right)=F_{1} z .
\end{aligned}
$$

If $F_{1} z=r_{0}$, then $F_{1}^{m} r_{0}=r_{0}$. So, $F_{1} z$ is a fixed point of $F_{1}^{m}$. Similarly, $F_{2}\left(F_{2}^{n} z\right)=F_{2} z$. Now, using equation (12) and Lemma 1, we obtain

$$
p\left(z, F_{1} z\right)=p\left(F_{1}^{m} z, F_{1}^{m}\left(F_{1} z\right)\right)
$$




$$
\begin{gathered}
\leq \psi\left\{p\left(z, F_{1} z\right), \frac{1}{2}\left[p\left(z, F_{1}^{m} z\right)+p\left(F_{1} z, F_{1}^{m}\left(F_{1} z\right)\right)\right],\right. \\
\left.\frac{1}{2}\left[p\left(z, F_{1}^{m}\left(F_{1} z\right)\right)+p\left(F_{1} z, F_{1}^{m} z\right)\right]\right\} \\
=\psi\left\{p\left(z, F_{1} z\right), \frac{1}{2}\left[p(z, z)+p\left(F_{1} z, F_{1} z\right)\right]\right. \\
\left.\frac{1}{2}\left[p\left(z, F_{1} z\right)+p\left(F_{1} z, z\right)\right]\right\} \\
=\psi\left\{p\left(z, F_{1} z\right), 0, p\left(z, F_{1} z\right)\right\} .
\end{gathered}
$$

Since $\psi$ satisfies the condition ( $\operatorname{Ir} 2)$, then we get

$$
\begin{aligned}
p\left(z, F_{1} z\right) & \leq \mu p\left(z, F_{1} z\right) \\
& \Rightarrow p\left(z, F_{1} z\right)=0, \text { since } 0<\mu<1 .
\end{aligned}
$$

Thus, we have $z=F_{1} z$ for all $z \in X$. Similarly, we can show that $z=F_{2} z$. This shows that $z$ is a common fixed point of $F_{1}$ and $F_{2}$. For uniqueness of $z$, let $z^{\prime} \neq z$ be another common fixed point of $F_{1}$ and $F_{2}$. Then clearly $z^{\prime}$ is also a common fixed point of $F_{1}^{m}$ and $F_{2}^{n}$ which implies $z^{\prime}=z$. Hence $F_{1}$ and $F_{2}$ have a unique common fixed point. This completes the proof.

Theorem 5. Let $\left\{U_{\alpha}\right\}$ be a family of continuous mappings on a complete partial metric space $(X, p)$ satisfying

$$
\begin{aligned}
p\left(U_{\alpha} x, U_{\beta} y\right) \leq \psi\left\{p(x, y), \frac{1}{2}\left[p\left(x, U_{\alpha} x\right)+p\left(y, U_{\beta} y\right)\right]\right. & \\
& \left.\frac{1}{2}\left[p\left(x, U_{\beta} y\right)+p\left(y, U_{\alpha} x\right)\right]\right)
\end{aligned}
$$

for $\alpha, \beta \in \Psi$ with $\alpha \neq \beta$ and $x, y \in X$. Then there exists a unique $z \in X$ satisfying $U_{\alpha} z=z$ for all $\alpha \in \Psi$.

Proof. For $x_{0} \in X$, we define a sequence as follows:

$$
x_{2 n+1}=U_{\alpha} x_{2 n}, x_{2 n+2}=U_{\beta} x_{2 n+1}, n=0,1,2, \ldots .
$$

It follows from (13), (pm4) and Lemma 1 that

$$
\begin{aligned}
p\left(x_{2 n+1}, x_{2 n}\right) & =p\left(U_{\alpha} x_{2 n}, U_{\beta} x_{2 n-1}\right) \\
& \leq \psi\left\{p\left(x_{2 n}, x_{2 n-1}\right), \frac{1}{2}\left[p\left(x_{2 n}, U_{\alpha} x_{2 n}\right)+p\left(x_{2 n-1}, U_{\beta} x_{2 n-1}\right)\right],\right. \\
& \left.\frac{1}{2}\left[p\left(x_{2 n}, U_{\beta} x_{2 n-1}\right)+p\left(x_{2 n-1}, U_{\alpha} x_{2 n}\right)\right]\right\} \\
& =\psi\left\{p\left(x_{2 n}, x_{2 n-1}\right), \frac{1}{2}\left[p\left(x_{2 n}, x_{2 n+1}\right)+p\left(x_{2 n-1}, x_{2 n}\right)\right],\right. \\
\left.\frac{1}{2}\left[p\left(x_{2 n}, x_{2 n}\right)+p\left(x_{2 n-1}, x_{2 n+1}\right)\right]\right\} & \\
\leq & \psi\left\{p\left(x_{2 n}, x_{2 n-1}\right), \frac{1}{2}\left[p\left(x_{2 n}, x_{2 n+1}\right)+p\left(x_{2 n-1}, x_{2 n}\right)\right],\right.
\end{aligned}
$$




$$
\begin{gathered}
\left.\frac{1}{2}\left[p\left(x_{2 n-1}, x_{2 n}\right)+p\left(x_{2 n}, x_{2 n+1}\right)-p\left(x_{2 n}, x_{2 n}\right)\right]\right\} \\
\leq \psi\left\{p\left(x_{2 n}, x_{2 n-1}\right), \frac{1}{2}\left[p\left(x_{2 n}, x_{2 n+1}\right)+p\left(x_{2 n-1}, x_{2 n}\right)\right],\right. \\
\left.\frac{1}{2}\left[p\left(x_{2 n-1}, x_{2 n}\right)+p\left(x_{2 n}, x_{2 n+1}\right)\right]\right\} .
\end{gathered}
$$

Since $\psi$ satisfies the condition ( $\operatorname{Ir} 1)$, there exists $\mu \in(0,1)$ such that

$$
p\left(x_{2 n+1}, x_{2 n}\right) \leq \mu p\left(x_{2 n}, x_{2 n-1}\right) \leq \mu^{2 n} p\left(x_{1}, x_{0}\right) .
$$

Now we show that $\left\{x_{n}\right\}$ is a Cauchy sequence in $X$. Let $m, n>0$ with $m>n$, then by using (pm4) and equation (15), we have

$$
\begin{aligned}
p\left(x_{n}, x_{m}\right) \leq & p\left(x_{n}, x_{n+1}\right)+p\left(x_{n+1}, x_{n+2}\right)+\cdots+p\left(x_{n+m-1}, x_{m}\right) \\
& -p\left(x_{n+1}, x_{n+1}\right)-p\left(x_{n+2}, x_{n+2}\right)-\cdots-p\left(x_{n+m-1}, x_{n+m-1}\right) \\
\leq & \mu^{n} p\left(x_{0}, x_{1}\right)+\mu^{n+1} p\left(x_{0}, x_{1}\right)+\cdots+\mu^{n+m-1} p\left(x_{0}, x_{1}\right) \\
= & \mu^{n}\left[p\left(x_{0}, x_{1}\right)+\mu p\left(x_{0}, x_{1}\right)+\cdots+\mu^{m-1} p\left(x_{0}, x_{1}\right)\right] \\
= & \mu^{n}\left[1+\mu+\cdots+\mu^{m-1}\right] p\left(x_{0}, x_{1}\right) \\
\leq & \mu^{n}\left(\frac{1-\mu^{m-1}}{1-\mu}\right) p\left(x_{0}, x_{1}\right) .
\end{aligned}
$$

Taking $n, m \rightarrow \infty$ in the above inequality, we get $p\left(x_{n}, x_{m}\right) \rightarrow 0$ since $0<\mu<1$, hence $\left\{x_{n}\right\}$ is a Cauchy sequence in $X$. Thus by Lemma 1 this sequence will also Cauchy in $\left(X, d_{p}\right)$. In addition, since $(X, p)$ is complete, $\left(X, d_{p}\right)$ is also complete. Thus there exists $r \in X$ such that $x_{n} \rightarrow r$ as $n \rightarrow \infty$. Moreover by Lemma 1 ,

$$
p(r, r)=\lim _{n \rightarrow \infty} p\left(r, x_{n}\right)=\lim _{n, m \rightarrow \infty} p\left(x_{n}, x_{m}\right)=0,
$$

implies

$$
\lim _{n \rightarrow \infty} d_{p}\left(r, x_{n}\right)=0 .
$$

By the continuity of $U_{\alpha}$ and $U_{\beta}$, it is clear that $U_{\alpha} r=U_{\beta} r=r$. Therefore $r$ is a common fixed point of $U_{\alpha}$ for all $\alpha \in \Psi$.

In order to prove the uniqueness, let us take another common fixed point $r^{\prime}$ of $U_{\alpha}$ and $U_{\beta}$ where $r \neq r^{\prime}$. Then from equation (13) and (16), we obtain

$$
\begin{aligned}
& p\left(r, r^{\prime}\right)=p\left(U_{\alpha} r, U_{\beta} r^{\prime}\right) \\
& \leq \psi\left\{p\left(r, r^{\prime}\right), \frac{1}{2}\left[p\left(r, F_{\alpha} r\right)+p\left(r^{\prime}, U_{\beta} r^{\prime}\right)\right],\right. \\
&\left.\frac{1}{2}\left[p\left(r, U_{\beta} r^{\prime}\right)+p\left(r^{\prime}, U_{\alpha} r\right)\right]\right\} \\
&=\psi\left\{p\left(r, r^{\prime}\right), \frac{1}{2}\left[p(r, r)+p\left(r^{\prime}, r^{\prime}\right)\right],\right. \\
&\left.\frac{1}{2}\left[p\left(r, r^{\prime}\right)+p\left(r^{\prime}, r\right)\right]\right\}
\end{aligned}
$$




$$
=\psi\left\{p\left(r, r^{\prime}\right), 0, p\left(r, r^{\prime}\right)\right\} .
$$

Since $\psi$ satisfies the condition $(\operatorname{Ir} 2)$, then we get

$$
\begin{aligned}
p\left(r, r^{\prime}\right) & \leq \mu p\left(r, r^{\prime}\right) \\
& \Rightarrow p\left(r, r^{\prime}\right)=0, \text { since } 0<\mu<1 .
\end{aligned}
$$

Thus, we get $r=r^{\prime}$ for all $r \in X$. This shows that $r$ is a unique common fixed point of $U_{\alpha}$ for all $\alpha \in \Psi$. This completes the proof.

Next, we give an analogues of fixed point theorems in metric spaces for partial metric spaces by combining Theorem 1 with $\psi \in \Psi$ and $\psi$ satisfies conditions $(\operatorname{Ir} 1),(\operatorname{Ir} 2)$ and $(\operatorname{Ir} 3)$. The following corollary is an analogues of Banach's contraction principle.

Corollary 2.1. Let $(X, p)$ be a complete partial metric space. Suppose that the mapping $T: X \rightarrow X$ satisfies the following condition:

$$
p(T x, T y) \leq f p(x, y)
$$

for all $x, y \in X$, where $f \in[0,1)$ is a constant. Then $T$ has a unique fixed point in $X$. Moreover, $T$ is continuous at the fixed point.

Proof. The assertion follows using Theorem 2 with $\psi\left(v_{1}, v_{2}, v_{3}\right)=f v_{1}$ for some $f \in[0,1)$ and all $v_{1}, v_{2}, v_{3} \in \mathbb{R}_{+}$. This completes the proof.

The following corollary is an analogues of R. Kannan's result in [15].

Corollary 2.2. Let $(X, p)$ be a complete partial metric space. Suppose that the mapping $T: X \rightarrow X$ satisfies the following condition:

$$
p(T x, T y) \leq g[p(x, T x)+p(y, T y)]
$$

for all $x, y \in X$, where $g \in\left[0, \frac{1}{2}\right)$ is a constant. Then $T$ has a unique fixed point in $X$. Moreover, $T$ is continuous at the fixed point.

Proof. The assertion follows using Theorem 2 with $\psi\left(v_{1}, v_{2}, v_{3}\right)=g v_{2}$ for some $g \in[0,1)$ and all $v_{1}, v_{2}, v_{3} \in \mathbb{R}_{+}$. Indeed, $\psi$ is continuous. First, we have $\psi\left(x, \frac{x+y}{2}, \frac{x+y}{2}\right)=g\left(\frac{x+y}{2}\right)$. So, if $y \leq \psi\left(x, \frac{x+y}{2}, \frac{x+y}{2}\right)$, then $y \leq\left(\frac{g}{2-g}\right) x$ with $\left(\frac{g}{2-g}\right)<1$. Thus, $T$ satisfies the condition $(\operatorname{Ir} 1)$.

Next, if $y \leq \psi(y, 0, y)=g .0=0$, then $y=0$. Thus, $T$ satisfies the condition $(\operatorname{Ir} 2)$.

Finally, if $y \leq \psi\left(0, \frac{y}{2}, \frac{y}{2}\right)=g\left(\frac{y}{2}\right)=0$, then $y=0$ since $g<\frac{1}{2}<1$. Thus, $T$ satisfies the condition $(\operatorname{Ir} 3)$.

The following corollary is an analogues of S. K. Chatterjae's result in [13]. Corollary 2.3. Let $(X, p)$ be a complete partial metric space. Suppose that the mapping $T: X \rightarrow X$ satisfies the following condition:

$$
p(T x, T y) \leq h[p(x, T y)+p(y, T x)]
$$


for all $x, y \in X$, where $h \in\left[0, \frac{1}{2}\right)$ is a constant. Then $T$ has a unique fixed point in $X$. Moreover, $T$ is continuous at the fixed point.

Proof. The assertion follows using Theorem 2 with $\psi\left(v_{1}, v_{2}, v_{3}\right)=h v_{3}$ for some $h \in[0,1)$ and all $v_{1}, v_{2}, v_{3} \in \mathbb{R}_{+}$. Indeed, $\psi$ is continuous. First, we have $\psi\left(x, \frac{x+y}{2}, \frac{x+y}{2}\right)=h\left(\frac{x+y}{2}\right)$. So, if $y \leq \psi\left(x, \frac{x+y}{2}, \frac{x+y}{2}\right)$, then $y \leq\left(\frac{h}{2-h}\right) x$ with $\left(\frac{h}{2-h}\right)<1$. Thus, $T$ satisfies the condition (Ir 1$)$.

Next, if $y \leq \psi(y, 0, y)=h .0=0$, then $y=0$. Thus, $T$ satisfies the condition $(\operatorname{Ir} 2)$.

Finally, if $y \leq \psi\left(0, \frac{y}{2}, \frac{y}{2}\right)=h\left(\frac{y}{2}\right)=0$, then $y=0$ since $h<\frac{1}{2}<1$. Thus, $T$ satisfies the condition $(\operatorname{Ir} 3)$.

Example 3. Let $X=[0,1]$. Define $p: X \times X \rightarrow \mathbb{R}^{+}$as $p(x, y)=\max \{x, y\}$ with $T: X \rightarrow X$ by $T(x)=\frac{x}{4}$. Clearly $(X, p)$ is a partial metric space. Now, let $x \leq y$. Then choose $x=\frac{1}{2}$ and $y=1$, we have $p(T x, T y)=\frac{y}{4}$, $p(x, y)=y, p(x, T x)=x, p(y, T y)=y, p(x, T y)=x, p(y, T x)=y$.

(i) Now, we consider

$$
p(T x, T y)=\frac{y}{4} \leq f y,
$$

or $f \geq \frac{1}{4}$. If take $0 \leq f<1$, then $T$ satisfies all the conditions of Corollary 2.1. Hence by application of Corollary 2.1, $T$ has a unique fixed point. Here it is seen that $0 \in X$ is the unique fixed point of $T$.

(ii) Now, we consider

$$
p(T x, T y)=\frac{y}{4} \leq g(x+y),
$$

putting $x=\frac{1}{2}$ and $y=1$ in the above inequality, we get

$$
\frac{1}{4} \leq \frac{3}{2} g,
$$

or $g \geq \frac{1}{6}$. If take $0 \leq g<\frac{1}{2}$, then $T$ satisfies all the conditions of Corollary 2.2. Hence by application of Corollary 2.2, $T$ has a unique fixed point and the unique fixed point $T$ is $0 \in X$.

(iii) Now, we consider

$$
p(T x, T y)=\frac{y}{4} \leq h(x+y),
$$

putting $x=\frac{1}{2}$ and $y=1$ in the above inequality, we get

$$
\frac{1}{4} \leq \frac{3}{2} h,
$$

or $h \geq \frac{1}{6}$. If take $0 \leq h<\frac{1}{2}$, then $T$ satisfies all the conditions of Corollary 2.3. Hence by application of Corollary 2.3, $T$ has a unique fixed point and it is $0 \in X$. 


\section{Conclusion}

In this article, we prove some fixed point and common fixed point theorems satisfying the implicit relation in the framework of complete partial metric spaces. Our results extend, unify and generalize several results from the existing literature in the context of partial metric spaces.

\section{Acknowledgements}

The author would like to thanks the anonymous referee and the editor for their careful reading and useful suggestions on the manuscript.

\section{REFERENCES}

[1] M. Abbas, T. Nazir and S. Ramaguera, Fixed point results for generalized cyclic contractive mappings in partial metric spaces, Revista de la Real Academia de Ciencias Exactas, FẤysicas y Naturales, Serie A - Matemáticas (RACSAM), 106 (1) (2012), $287-297$.

[2] T. Abdeljawad, E. Karapinar and K. Tas, Existence and uniqueness of common fixed point partial metric spaces, Applied Mathematics Letters, 24 (11) (2011), 1900-1904.

[3] O. Acar, V. Berinde and I. Altun, Fixed point theorems for Ciric-type strong almost contractions on partial metric spaces, Journal of Fixed Point Theory and Applications, 12 (2012), 247-259.

[4] I. Altun, F. Sola and H. Simsek, Generalized contractions on partial metric spaces, Topology and its Applications, 157 (2010), 2778-2785.

[5] I. Altun and A. Erduran, Fixed point theorems for monotone mappings on partial metric spaces, Fixed Point Theory and Applications, 2011 (2011), ArticleID 508730, 10 pages.

[6] H. Aydi, M. Abbas and C. Vetro, Partial Hausdorff metric and Nadler's fixed point theorem on partial metric spaces, Topology and its Applications, 159 (14) (2012), 3234-3242.

[7] G. V. R. Babu and P. D. Sailaja, Coupled fixed point theorems with new implicit relations and an application, Journal of Operators, 2014 (2014), ArticleID 389646, 16 pages.

[8] S. Banach, Surles operation dans les ensembles abstraits et leur application aux equation integrals, Fundamenta Mathematicae, 3 (1922), 133-181.

[9] V. Berinde and F. Vetro, Common fixed points of mappings satisfying implicit contractive conditions, Fixed Point Theory and Applications, 2012 (2012), ArticleID 2012:105, 12 pages.

[10] S. Beloul and A. Tomar, A coincidence and common fixed point theorem for subsequentially continuous hybrid pairs of maps satisfying an implicit relation, Mathematica Moravica, 21 (2) (2017), 15-25.

[11] H. Bouhadjera, Different common fixed point theorems of integral type for pairs of subcompatible mappings, Mathematica Moravica, 22 (2) (2018), 41-57. 
[12] N. Chandra, Mahesh C. Joshi and N. K. Singh, Common fixed points for faintly compatible mappings, Mathematica Moravica, 21 (2) (2017), 51-59.

[13] S. K. Chatterjae, Fixed point theorems compactes, Comptes rendus de l'Academie bulgare des Sciences, 25 (1972), 727-730.

[14] R. Heckmann, Approximation of metric spaces by partial metric spaces, Applied Categorical Structures, 7 (1) (1999), 71-83.

[15] R. Kannan, Some results on fixed point theorems, Bulletin of the Calcutta Mathematical Society, 60 (1969), 71-78.

[16] E. Karapinar, Generalization of Caristi-Kirk's theorem on partial metric spaces, Fixed Point Theory and Applications, 2011 (4) (2011).

[17] E. Karapinar, Weak $\phi$-contraction on partial metric spaces, Journal of Computational Analysis and Applications, 14 (2) (2012), 206-210.

[18] E. Karapinar, W. Shatanawi and K. Tas, Fixed point theorems on partial metric spaces involving rational expressions, Miskolc Mathematical Notes, 14 (2013), $135-142$.

[19] E. Karapinar and U. Yüksel, Some common fixed point theorems in partial metric space, Journal of Applied Mathematics, 2011 (2011), ArticleID 263621, 16 pages.

[20] E. Karapinar and Inci M. Erhan, Fixed point theorems for operators on partial metric spaces, Applied Mathematics Letters, 24 (2011), 1894-1899.

[21] M. Kir and H. Kiziltunc, Generalized fixed point theorems in partial metric spaces, European Journal of Pure and Applied Mathematics, 9 (4) (2016), 443-451.

[22] H. P. A. Künzi, Nonsymmetric distances and their associated topologies about the origins of basic ideas in the area of asymptotic topology, Handbook of the History of General Topology (eds. C.E. Aull and R. Lowen), Kluwer Academic Publishers, 3 (2001), 853-868.

[23] S. Manro, A common fixed point theorem in Fuzzy metric space using implicit relation, International Journal of Mathematics and Statistics, 16 (2) (2015), 35-42.

[24] S. G. Matthews, Partial metric topology, Research report 2012, Deptartment of Computer Science, University of Warwick, 1992.

[25] S. G. Matthews, Partial metric topology, Proceedings of the 8th summer conference on topology and its applications, Annals of the New York Academy of Sciences, 728 (1994), 183-197.

[26] H. K. Nashine, Z. Kadelburg, S. Radenovic and J. K. Kim, Fixed point theorems under Hardy-Rogers contractive conditions on 0-complete ordered partial metric spaces, Fixed Point Theory and Applications, 2012 (2012), 1-15.

[27] H. K. Nashine, Common fixed point theorems under implicit relations on ordered partial metric spaces and application to integral equation, Bulletin of Mathematical Sciences, 3 (2013), 18-204.

[28] M. Nazam, M. Arshad, S. Radenović, D. Turkoglu and V. Ozturk, Some fixed point results for dual contractions of rational type, Mathematica Moravica, 21 (1) (2017), $139-151$. 
[29] S. Oltra and O. Valero, Banach's fixed point theorem for partial metric spaces, Rendiconti dell'Istituto di Matematica dell'Università di Trieste, 36 (2004), 17-26.

[30] M. Pitchaimani and D. Ramesh Kumar, Some common fixed point theorems using implicit relation in 2-Banach spaces, Surveys in Mathematics and its Applications, 10 (2015), 159-168.

[31] V. Popa, Some fixed point theorems for compatible mappings satisfying an implicit relation, Demonstratio Mathematica, 32 (1) (1999), 157-164.

[32] V. Popa, A general fixed point theorem for two hybrid pairs of mappings satisfying a mixed implicit relation and applications, Mathematica Moravica, 21 (2) (2017), 103-114.

[33] V. Popa and A.-M. Patriciu, Fixed point theorems for a pair of mappings satisfying $\phi$-implicit relations in weak partial metric spaces, Journal of the International Mathematical Virtual Institute, 7 (2017), 165-180.

[34] G. S. Saluja, Weak and strong convergence theorems of modified SP-iterations for generalized asymptotically quasi-nonexpansive mappings, Mathematica Moravica, 20 (1) (2016), 125-144.

[35] G. S. Saluja, Strong convergence theorems for two finite families of generalized asymptotically quasi-nonexpansive mappings with applications, Mathematica Moravica, 22 (1) (2018), 1-14.

[36] G. S. Saluja, Some fixed point results on S-metric spaces satisfying implicit relation, Journal of Advanced Mathematical Studies, 12 (3) (2019), 256-267.

[37] K. K. M. Sarma and Yohannes Gebru, Best proximity points for generalized $\alpha-\eta-$ $\psi$-Geraghty proximal contraction mappings, Mathematica Moravica, 21 (2) (2017), 85-102.

[38] M. Schellekens, A characterization of partial metrizibility: domains are quantifiable, Theoritical Computer Science, 305 (1-3) (2003), 409-432.

[39] O. Valero, On Banach fixed point theorems for partial metric spaces, Applied General Topology, 6 (12) (2005), 229-240.

[40] P. Waszkiewicz, Partial metrizibility of continuous posets, Mathematical Structures in Computer Science, 16 (2) (2006), 359-372.

\author{
G. S. SAluJa \\ Department of Mathematics \\ Govt. K.P.G. College, Jagdalpur \\ JAGDALPUR - 494001 (C.G.) \\ INDIA \\ E-mail address: saluja1963@gmail.com
}

